\title{
An Analysis of the Advantages, Challenges and Obstacles of Cloud Computing Adoption to an Academic Control System
}

\author{
Eduardo Zied Milian, Mauro M. Spinola, \\ Rodrigo F. Gonçalves, and André Leme Fleury \\ Production Engineering Department, \\ Polytechnic School of São Paulo University, São Paulo, Brazil \\ \{eduardo.zied, mauro.spinola\}@usp.br \\ rofranco@osite.com.br, andreleme.fleury@gmail.com
}

\begin{abstract}
The evolution of cloud computing (CC) over the past few years is certainly one of the greatest advancements in the history of computing. However, for this technology to reach its potential there must be a clear understanding of the issues involved in its adoption. The purpose of this exploratory case study is to build an evaluation model that takes into account aspects such as the advantages, challenges and obstacles of adopting CC. To assess the feasibility and usefulness of such model, an Academic Control System (ACS) from an International School was analyzed. Such analysis enabled the development of recommendations, the provision of inputs and the suggestion of actions necessary to launch the ACS as a cloud service. The model revealed challenges regarding governance, human resources (HR) management, project management and organizational culture to deal with innovations and changes. Such challenges shall be taken into account in the cloud strategy. Also, security issues, business models, technical capacity, performance, service level agreements (SLA) are obstacles that organizations willing to provide such services must face. According to the model, the recommendations to overcome such challenges and obstacles include HR management good practices, risk management processes and well-defined decision making instances.
\end{abstract}

Keywords: Cloud Computing, Software as a Service, Product Management.

\section{$1 \quad$ Introduction}

Considered one of the greatest developments in the history of computing [1], Cloud Computing (CC) has been gaining ground as a successful model as it promises economic savings, easiness of use and greater flexibility in the control of resource use, anytime and anywhere, while delivering the required computing power. The model's value proposition is that resources are no longer idle, as they almost used to the fullest (with lower unit costs) [2]. However, for this technology to reach its potential there must be a clear understanding of the various issues involved in its adoption, from the point of view of both providers and customers [2].

B. Grabot et al. (Eds.): APMS 2014, Part II, IFIP AICT 439, pp. 564-571 2014.

(C) IFIP International Federation for Information Processing 2014 
The purpose of this research is to investigate the applicability and usefulness of an evaluation model for the $\mathrm{CC}$ adoption, built under the scope of the study. The model considers aspects such challenges, obstacles and advantages of CC. Supported by the literature, these aspects were unfolded into issues involving governance, people management, project management, risk management and forms of investments, as well as into other topics related to design, development and marketing of software products to be offered with a service, within this new paradigm of computing.

Having started its operation in 2003, an International Education institution began modernizing its Information Technology (IT) area in 2009. As its growth exceeded $100 \%$ per year, the department, initially directed to academic needs, started meeting business requirements through the adoption of specific ERP modules and development of an Academic Control System (ACS), aiming at improving organizational processes and controls.

In light of the challenges to maintain the hardware and software infrastructure updated and secure and with the required availability, IT management currently rethinks the way in which these computing resources are acquired, developed and used, studying the feasibility of the adoption of CC.

IT managers believe that the internally developed ACS, as part of efforts to improve processes and controls, could become a product to meet common needs of international schools. As with the IT infrastructure, the International School is assessing the possibility of using CC. The ACS would open a new business opportunity for the organization, currently focused exclusively on the education segment, possibly with the setting up of a company with this specific purpose. Thus, this new product would be developed for the cloud, and it would be necessary to assess the issues inherent to this decision.

The main motivation of this case study was to examine the robustness of the proposed evaluation model, as well as to assist the International School in making decisions regarding the release of the ACS, seeking to identify the key advantages and potential obstacles for the adoption of $\mathrm{CC}$, so that organizations can offer competitive, updated and effective products, with the most efficient use of its resources.

\section{Literature Review}

To achieve the proposed objective to work (construction of an evaluation model for the adoption of $\mathrm{CC}$, investigating its applicability and its usefulness for the launch of the ACS as a cloud service), the authors searched the literature that examine major issues concerning the subject, as follow.

Definition of Cloud Computing. Although many formal definitions have been proposed by academia and industry $[3,4,5,6]$, the definition provided by NIST (National Institute of Standards and Technology) [7] includes the main concepts commonly used in the CC community. According to NIST, "cloud computing is a model for enabling ubiquitous, convenient, on-demand network access to a shared pool of configurable computing resources (e.g., networks, servers, storage, applications and services) that can be rapidly provisioned and released with minimal management effort or service provider interaction." 
Table 1. Advantages of Cloud Computing

\begin{tabular}{cl}
\hline ADVANTAGES & \multicolumn{1}{c}{ DESCRIPTION } \\
\hline $\mathbf{A 1}$ & $\begin{array}{l}\text { Lower cost of customers' capital: Customers do not buy software or infrastructure } \\
\text { (hardware and operating system, for example) in advance, but they pay for the access } \\
\text { to those services over time [1]. }\end{array}$ \\
\hline $\mathbf{A 2}$ & $\begin{array}{l}\text { Lower cost of providers' capital: CC can provide an almost immediate access to } \\
\text { hardware resources with no upfront investments to its users, reducing the "time to } \\
\text { market" for products from many companies [1]. }\end{array}$ \\
\hline $\mathbf{A 3}$ & $\begin{array}{l}\text { Reduces deployment cycle: since applications are already deployed in SaaS vendors' } \\
\text { sites. The SaaS model also allows cost savings in the large-scale operation of standar- } \\
\text { dized business components [9]. }\end{array}$ \\
\hline $\mathbf{A 4}$ & $\begin{array}{l}\text { Reduces cost of entry into new business: significantly reduces the cost of entry for } \\
\text { small companies that can benefit from the business applications, previously available } \\
\text { only to large corporations [1]. }\end{array}$ \\
\hline $\mathbf{A 5}$ & $\begin{array}{l}\text { Reduces cost of business expansion or entry into new markets: CC makes it easier } \\
\text { for businesses to expand their services according to customers' demands, since com- } \\
\text { puting resources can be deployed very quickly and in accordance with needs [1]. }\end{array}$ \\
\hline $\mathbf{A 6}$ & $\begin{array}{l}\text { Easier maintenance: the IS provider has greater flexibility to correct, improve or add } \\
\text { new features as it has greater control of the application's configuration [10]. }\end{array}$ \\
\hline
\end{tabular}

Table 2. Challenges of Cloud Computing adapted from [12]

\begin{tabular}{|c|c|}
\hline $\begin{array}{c}\text { CHALLENGE } \\
\mathrm{S}\end{array}$ & DESCRIPTION \\
\hline C1 & $\begin{array}{l}\text { Human Resources: in practice, the recruitment and retention of a high quality team, } \\
\text { albeit small, is one of the biggest challenges of HR management. In general, there is a } \\
\text { lot of demand for staff skilled to work with CC resources, requiring organizations to } \\
\text { pay them slightly more than competitors, within a career plan, keeping them always } \\
\text { challenged and stimulated. }\end{array}$ \\
\hline C2 & $\begin{array}{l}\text { Changes in culture, values, guiding principles, beliefs: CC allows a change in the } \\
\text { vision of the IT function. Traditionally, IT departments spend } 60 \% \text { to } 80 \% \text { of their } \\
\text { efforts to keep their infrastructure running, resulting in little time to focus on business } \\
\text { needs. With CC, IT can be quicker to respond to changing needs in business require- } \\
\text { ments. This challenge is enabling the change in the current situation of organizations, to } \\
\text { achieve the skills to meet the business needs and the functions of architects and experts } \\
\text { in CC. }\end{array}$ \\
\hline $\mathrm{C3}$ & $\begin{array}{l}\text { Project Management: it must be a core skill of the organization and not just the main- } \\
\text { tenance of a business resource. Candidates for the role of project manager are most } \\
\text { likely found among relationship builders and technology evangelists. The creators of } \\
\text { business systems, leaders, architects and specialized buyers must have an active role in } \\
\text { projects with a strong technology or component of CC. }\end{array}$ \\
\hline C4 & $\begin{array}{l}\text { Innovation: IT areas shall be designed to handle dynamic business contexts, which, } \\
\text { among other tasks, are designed to innovate. Organizations still need to make big } \\
\text { changes if they want to take advantage of the great innovations of technology/service } \\
\text { providers in the cloud. Fundamental practices such as support the effective collaborative } \\
\text { innovation and deepen the collaboration between areas of the organization can offer not } \\
\text { only an operational IT but also business process and strategic innovations. }\end{array}$ \\
\hline C5 & $\begin{array}{l}\text { Cloud evolution: IT executives need to focus on the reality of technical expertise and } \\
\text { services, while ensuring that business managers have the correct perception of the } \\
\text { necessary improvements to IT performance. Capacities to plan architecture, correct } \\
\text { technical errors and facilitate contract management are particularly important. A greater } \\
\text { pro-activity in the delivery of strategic technologies for business and increased focus on } \\
\text { needs are required. }\end{array}$ \\
\hline
\end{tabular}

Cloud Computing Services. Also according to NIST [7], the definition of CC includes three different service models: Infrastructure as a Service (IaaS), Platform as a 
Service (PaaS), and Software as a Service (SaaS). In the IaaS model, customers are allocated computing resources in order to run virtual machines consisting of operating systems and applications [8]. In the PaaS, consumers are allowed to write applications that run on the service provider's environment. The third model, SaaS, provide consumers with typical software applications running over the Internet. Google Apps Engine and Google Docs are, respectively, examples of PaaS and SaaS [3]. The paradigm of cloud computing reinforces the assertion of Delone [11], which to measure the overall success of IT, the service quality is more important than the quality of the information or the quality of the systems themselves.

Table 3. Obstacles for Cloud Computing adoption

\begin{tabular}{|c|c|}
\hline OBSTACLES & DESCRIPTION \\
\hline 01 & $\begin{array}{l}\text { Strategic feasibility of procurement or provision of services: organizations may } \\
\text { believe that certain information systems, depending on their criticality to the business } \\
\text { and on the need to maintain them under their control, cannot be hired or offered in the } \\
\text { cloud. This may occur when the system business rules can offer a competitive business } \\
\text { advantage for that organization within the segment in which it operates. [15]. }\end{array}$ \\
\hline $\mathbf{O 2}$ & $\begin{array}{l}\text { Lack of technical capacity: implementing a CC environment is a major technical } \\
\text { challenge. Complex software solutions have to be developed and available } 24 \times 7 \text { [13]. }\end{array}$ \\
\hline $\mathbf{O 3}$ & $\begin{array}{l}\text { Business model deficiencies: the economic viability of provider, its ability to thrive } \\
\text { and continue in the activity may inhibit customers' willingness to use cloud products } \\
{[13] \text {. }}\end{array}$ \\
\hline 04 & $\begin{array}{l}\text { Security issues: Migration to any of CC models presents many security risks. In addi- } \\
\text { tion to physical security and to the security of organizations' data, there are technical, } \\
\text { legal and policy issues [16]. The risk model must cover all aspects of security require- } \\
\text { ments, including physical security, data security and policy, technical and legal issues } \\
{[16] \text {. }}\end{array}$ \\
\hline 05 & $\begin{array}{l}\text { Behavioral Tradition - Abandoning the traditional IT model: There is an important } \\
\text { cultural obstacle, which can generate mistrusts and uncertainties. This obstacle can be } \\
\text { represented by customers' need to abandon the traditional IT model, in which physical } \\
\text { and logical IT resources to support business organizations are more tangible [13]. }\end{array}$ \\
\hline 06 & $\begin{array}{l}\text { Availability: services require an internet connection constantly available. Otherwise, } \\
\text { these connection failures may result in the application unavailability [10] [13]. }\end{array}$ \\
\hline 07 & $\begin{array}{l}\text { Performance: applications may not work well with low-speed connections: which will } \\
\text { result in the downtime or slowdown of the application or of some of its resources due to } \\
\text { possible latency in the target analysis application data transfers [10] [13]. }\end{array}$ \\
\hline O8 & $\begin{array}{l}\text { Governance: As a result of technical and contractual complexity, consumers fear that } \\
\text { unheard-of situations and consequent short time of maturations, providers are not pre- } \\
\text { pared to deal with them satisfactorily, causing difficulties in the relationship [14]. }\end{array}$ \\
\hline O9 & $\begin{array}{l}\text { Service level agreements (SLAs) and quality: these refer to providers' ability to } \\
\text { ensure availability and have the resources to meet contingencies. They are provided for } \\
\text { in the SLA, where compliance standards and penalties are defined [14]. }\end{array}$ \\
\hline 010 & $\begin{array}{l}\text { Reliability: consumers expect } \mathrm{CC} \text { environments to be reliable and that the availability } \\
\text { of services and resources offered fully meet their needs, especially those related to } \\
\text { critical business aspects. Thus, CC crucially depends on reliability; if consumers feel } \\
\text { the system is not fully reliable, they become reluctant to use this service model [14]. }\end{array}$ \\
\hline
\end{tabular}

Advantages, Challenges and Obstacles to the Adoption of CC. Marston [1] considers that $\mathrm{CC}$, by enabling the convergence to an environment where information can be accessed, notwithstanding the device used and the location, represents a major shift in computing and can offer significant advantages to adopting organizations. Table 1 
shown the main advantages of $\mathrm{CC}$, identified as $\mathrm{A} 1$ to $\mathrm{A} 6$, to facilitate the understanding of the recommendations presented in 4.

According to Willcocks et al. [12], there are five major challenges that must be faced by those who currently use the traditional IT infrastructure model and who want to switch to CC. Challenges were identified as C1 to C5 in Table 2, in order to facilitate the understanding of the recommendations presented in 4.

The literature on CC offers studies $[13,14,15]$ which mention the difficulties to its adoption, represented by obstacles inherent to the computing model. The main obstacles, listed from $\mathrm{O} 1$ to $\mathrm{O} 10$, are shown in Table 3.

\section{$3 \quad$ Research Methodology}

Research Method. The research consisted of an exploratory case study. Based on the literature review, was identified advantages, challenges and obstacles relevant to the development of an evaluation model for the adoption of CC. These aspects are the basis for building the model, in which challenges and obstacles were grouped into four correlated action foci: organization, business model, human resources and security. These action foci grouped the recommendations of the action plan (Table 5), facilitating the understanding and its unfolding in the actions themselves.

Questionnaires were used to implement the analysis model. They were designed to investigate the qualitative aspects (advantages, challenges and obstacles) of the evaluation model. The result of these questionnaires applying, called Case Narrative (Fig. 1), were analyzed using knowledge of literature bounded by the model. The result of the analysis is a set of recommendations, which unfolds in the proposed action plan.

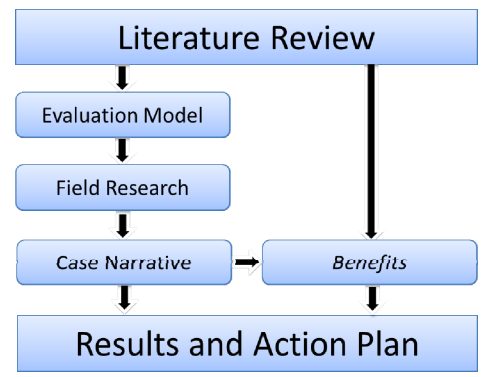

Fig. 1. Schematic diagram of the construction of results.

Characterization of the Target Organization. The unit of analysis is an International School that started its activities in 2003 with just over 70 students and a few staff, and grows exponentially since then. It currently has about 1,000 students, approximately 250 employees and its revenue is of approximately $\mathrm{R} \$ 48$ million/year. 
In addition, the organization and its IT environment (personnel, systems, processes, etc.) have the relevant characteristics to enable the study. Following the definition of issues and research project, interviews were held with people who hold the following positions: IT manager, process and authorship engineer (manager), development coordinator (manager) and development analyst (coordinator).

Description of the Target Application. The IT infrastructure currently has ERP (Financial - billing) systems and the Academic Control System (ACS), which becomes, every day, more important in the operation of the organization. The application that will be the object of analysis is the ACS (candidate to move to the cloud).

\section{$4 \quad$ Results and Action Plan}

The construction of the Case Narrative (Fig. 1) resulted from the application of questionnaires to investigate the relevant topics of the target organization and the target application. Table 4 presents the advantages of using the $\mathrm{CC}$ found in the literature and adapted by the author based on what can be extracted from the Field Research and recorded in the Case Narrative.

Table 4. Recommendations for taking advantages of CC

\begin{tabular}{|c|c|}
\hline $\begin{array}{c}\text { ADVANTAGE } \\
\mathbf{S}\end{array}$ & RECOMMENDATIONS \\
\hline A1 \& A3 & $\begin{array}{l}\text { Lower customer capital: ACS provider shall promote its product to customers in } \\
\text { the SaaS model, arguing that they will not need to purchase software or infrastruc- } \\
\text { ture, but will pay for access to services over time. This will result in reduced cost of } \\
\text { fixed capital, dilution of service costs over time, allowing a quicker return on in- } \\
\text { vestment, and potentially, bringing significant cost savings. }\end{array}$ \\
\hline A2 & $\begin{array}{l}\text { Lower providers' capital cost: CC, by providing almost immediate access to } \\
\text { hardware resources with no initial investment for ASC provider, improving its } \\
\text { "time to market". As it is an operating expense, it also helps drastically reducing } \\
\text { the necessary investments to product launching. }\end{array}$ \\
\hline $\mathbf{A 3}$ & $\begin{array}{l}\text { Reduces deployment cycle: ACS provider shall promote its product arguing that it } \\
\text { is already deployed under the SaaS delivery model, reducing deployment time, } \\
\text { parameterization and system "tuning" (ACS). }\end{array}$ \\
\hline A4 & $\begin{array}{l}\text { Cost of entry into new business: ACS provider shall promote its product arguing } \\
\text { that customers can drastically reduce the cost of entry into the market for interna- } \\
\text { tional schools that benefit from the knowledge of existing ACS business rules. }\end{array}$ \\
\hline A5 & $\begin{array}{l}\text { Cost of business expansion or entry into new markets: ACS provider shal } \\
\text { promote its product arguing that CC makes it easier for customers to expand their } \\
\text { services for purposes of business expansion or entry into new markets according to } \\
\text { their strategic plan. This is because computational resources can be deployed very } \\
\text { quickly, according to new needs, scaling them up or down dynamically, depending } \\
\text { on customer's load, with minimal interaction with service providers (self-service). }\end{array}$ \\
\hline A6 & $\begin{array}{l}\text { Easy maintenance: ACS provider has greater flexibility to correct, improve or } \\
\text { include new features, as it has a greater control on the distribution and management } \\
\text { of its applications, enabling agility in meeting the business needs of customers. }\end{array}$ \\
\hline
\end{tabular}

The recommendations were grouped in into four foci of correlated actions summarized in a preliminary action plan (Table 5) for further detail, with the definition of responsible parties, timeframes and indicators for monitoring and control. 
Table 5. Action Plan to implement recommendations

\begin{tabular}{|c|c|c|}
\hline ACTION FOCUS & ASPECT & ACTION TO BE PLANNED \\
\hline Organization & $\begin{array}{l}\text { C2, C4, } \\
\text { C5 \& O8 }\end{array}$ & $\begin{array}{l}\text { - Share organizational values, such as, for example, keeping channels of } \\
\text { communication that promote improvements, seeking greater efficiency } \\
\text { and effectiveness. } \\
\text { - Practice effective collaborative innovation between different areas } \\
\text { involved with CC, such as development, marketing, human resources and } \\
\text { interfaces with providers. } \\
\text { - Demonstrate the commitment to develop, implement and improve the } \\
\text { ability to offer ACS as a service, within the organization's business } \\
\text { context and customers' needs. } \\
\text { - Inform customers of sustainable strategies through decisions (medium } \\
\text { and long terms) involving CC. }\end{array}$ \\
\hline $\begin{array}{r}\text { Business } \\
\text { Model }\end{array}$ & $\begin{array}{l}\text { C5, O1, } \\
\text { O3 \& O5 }\end{array}$ & $\begin{array}{l}\text { - Improve processes for the selection of providers based on technical and } \\
\text { commercial criteria. } \\
\text { - Rely on outside legal assistance for the preparation of procurement } \\
\text { contracts and offering of services associated with ACS. } \\
\text { - Solidly rely on technology partners and infrastructure providers, which } \\
\text { shall preferably be large organizations, well known in the market, to be } \\
\text { presented to business plan partners for the development and commercia- } \\
\text { lization of the product. }\end{array}$ \\
\hline $\begin{array}{r}\text { (HR) Human } \\
\text { Resources }\end{array}$ & C1 \& 02 & $\begin{array}{l}\text { - Promote measures to reduce turnover of highly skilled people in CC. } \\
\text { - Promote training in CC key technologies. }\end{array}$ \\
\hline $\begin{array}{r}\text { Product } \\
\text { Development }\end{array}$ & $\begin{array}{l}\text { C3, C4, } \\
\text { C5, 07, } \\
\text { O9 \& } \\
\text { O10 }\end{array}$ & $\begin{array}{l}\text { - Define processes, records and documentation of projects. } \\
\text { - Plan, design and implement activities directly focused on the perfor- } \\
\text { mance of ACS. } \\
\text { - Establish metrics (indicators) to monitor and control the expected } \\
\text { performance. } \\
\text { - Develop a plan to identify and mitigate risks inherent to the selected } \\
\text { service model (own or outsourced infrastructure under the PaaS model). }\end{array}$ \\
\hline Security & C5 \& 04 & $\begin{array}{l}\text { - Deploy an IT risk management through a set of processes, policies and } \\
\text { structures, providing an insight into the organization of all risks involved } \\
\text { in the service provision. }\end{array}$ \\
\hline
\end{tabular}

\section{Conclusions}

The analysis model proved to be robust enough to capture the peculiarities (and desires) of the organization and compare them with literature. Its application enabled the formulation of recommendations, giving subsidies and presenting an action plan for the International School to be able to guide and implement its decisions, regarding the development and marketing of ACS as an application for CC.

Although CC is a relatively new model for the delivery of IT resources, based on its proposal and use, is possible to see that the main issues addressed are the same of the traditional IT model found in organizations. Issues such as organizational strategy, governance, technical and legal training, information security, personnel management, project management, contract management are present and are the same as the vastly used IT model, although here seen from the perspective of CC.

The model identified good management practices, such as establishing communication channels between the hierarchical levels and owners, promoting innovation through collaboration between areas, establishing strategic and long-term partnerships with providers, establishing payment policies to retain people, setting processes and 
metrics for the development and performance of the product and treatment of risks as a structured process with clearly defined responsibilities and methods. These aspects should be taken into account by organizations wishing to offer cloud services.

Difficulties encountered in applying the model result from the different nature of the issues involved (for ex., governance, HR, security, etc.). Thus, applicator must have specific knowledge of these aspects, so that, when raised and analyzed, they produce the appropriate result.

Any generalization is limited since the study's focus is on a single application in a single organization. Aiming to generalize the findings of this work, further study of the model can be performed in different countries and with software vendors or service providers willing to use the cloud to offer their applications.

\section{References}

1. Marston, S., Li, Z., Bandyopadhyay, S.: Cloud computing - The business perspective. Decision Support Systems 51(1), 176-189 (2011)

2. Kaisler, S., Money, W.H., Cohen, S.J.: A Decision Framework for Cloud Computing. In: 45th Hawaii Int. Conf. Syst. Sci., pp. 1553-1562 (2012)

3. Vaquero, L., Rodero-Merino, L.: A break in the clouds: towards a cloud definition. ACM SIGCOMM Computer Communication Review 39(1), 50-55 (2008)

4. Taurion, C.: Cloud Computing: Transforming the World of Information Technology, 1st edn. Brasport, Rio de Janeiro (2009)

5. Veras, M.: Datacenter: Central component of the IT Infrastructure, 1st edn. Brasport, Rio de Janeiro (2009)

6. Linthicum, D.S.: Cloud computing and SOA convergence in your enterprise: a step-bystep guide. Pearson Education (2009)

7. Mell, P., Grance, T.: The NIST Definition of Cloud Computing - Recommendations of the National Institute of Standards and Technology (2011),

http://csrc.nist.gov/publications/nistpubs/800-145/

SP800-145.pdf (March 12, 2013)

8. Chudnov, D.: A view from the clouds. Computers in Libraries 30(3), 33-35 (2010)

9. Xin, M., Levina, N.: Software-as-a-Service Model: Elaborating Client-side Adoption Factors. In: Proceedings of the 29th International Conference on Information Systems, Paris, France, December 14-17 (2008)

10. Sommerville, I.: Software engineering, 9th edn. Pearson/Addison-Wesley (2011)

11. Delone, W.: The DeLone and McLean model of information systems success: a ten-year update. Journal of Management Information Systems 19(4), 9-30 (2003)

12. Willcocks, L., Venters, W., Whitley, E.: Cloud Sourcing: Implications for Managing the IT Function. The Dynamics of Global Sourcing 130, 142-163 (2012)

13. Miller, M.: Cloud computing: web-based applications that change the way you work and collaborate online. Que Publishing, Indianapolis (2008)

14. Marks, E.A., Lozano, R.R.: Executive's guide to cloud computing. John Wiley, Hoboken (2010)

15. Chaves, S., Souza, C.: Obstacles to Cloud Computing Adoption: A Delphi Study Conducted with Brazilian Professionals and Academics. In: CONF-IRM 2012 Proceedings (2012), http: / /aisel.aisnet.org/confirm2012/62 (March 15, 2013)

16. Mather, T., Subra, K., Shahed, L.: Cloud security and privacy: an enterprise perspective on risks and compliance. O’Reilly Media, Inc. (2009) 